\title{
Is Osteocalcin Implicated in the Regulation Of Energy Metabolism in Active Rheumatoid Arthritis?
}

\author{
Alicja Nowak ${ }^{1 *}$, Anna Straburzyńska-Lupa ${ }^{2}$, Łucja Pilaczyńska-Szcześniak ${ }^{1}$ and Wojciech Romanowski ${ }^{3}$
}

${ }^{1}$ Department of Hygiene, University School of Physical Education, Poznań, Poland

${ }^{2}$ Department of Physiotherapy, University School of Physical Education, Poznań, Poland

${ }^{3}$ Rheumatological Centre Śrem, Śrem, Poland

\begin{abstract}
The purpose of this study was to determine the relationship of osteocalcin with insulin resistance, insulin-like growth factor-1 (IGF-1) and inflammatory markers in women with RA.

The study population comprised of 35 postmenopausal women with RA. The significant negative correlations were noted between the osteocalcin and resistin levels $(P<0.05)$, glucose and resistin levels $(P \leq 0.01)$, glucose and interleukin-6 levels $(P \leq 0.01)$, interleukin-6 and insulin-like growth factor binding protein-3 (IGFBP-3) levels $(P<0.05)$. The positive correlations were found between insulin level and disease duration $(P<0.05)$, index of insulin resistance (HOMA-IR) level and disease duration ( $P<0.05)$, IGF-1 and IGFBP-3 levels $(P \leq 0.01)$, the IGF-1/IGFBP-3 ratio and erythrocyte sedimentation rate $(P \leq 0.01)$, and the IGF-1/IGFBP-3 ratio and C-reactive protein levels $(P<0.05)$.
\end{abstract}

The present study suggests that inflammatory factors may modify in distinct ways the relationship between osteocalcin and carbohydrate metabolism in patients with RA. However, limitations of this study are: lack of control group, small sample size and that we did not measure uncarboxylated OC.

Keywords: Osteocalcin; Insulin resistance; IGF-1; Cytokines

\section{Introduction}

Rheumatoid arthritis (RA), an inflammatory disease that causes joint damage, can result in development of comorbidities including type 2 diabetes [1] or osteoporosis [1]. Pro-inflammatory factors play an important role in the development of such complications $[2,3]$ which induce insulin resistance [3] and may affect levels of hepatic insulin-like growth factor-1 (IGF-1) mRNA and plasma IGF-1 [4].

Animal studies have confirmed the mutual association between carbohydrate and bone metabolism, demonstrating the contribution of uncarboxylated osteocalcin (OC), released from bone, in the stimulation of insulin secretion and the regulation of energy metabolism [5]. Both insulin and IGF-1 initiate cellular responses in bone by binding to and activating their endogenous tyrosine kinase receptors [6]. It has been suggested that insulin signalling in osteoblasts enhances OC carboxylation and impacts glucose homeostasis by promoting the ability of osteoclasts to enhance bone resorption [7]. On the other hand energy metabolism and bone remodelling may be co-regulated by several cytokines, between others by resistin or interleukin 6 (IL-6), which play a role in the pathogenesis of RA [8]. It has been suggested that both cytokines are implicated in insulin resistance in obesity and inflammatory disorders, in that in RA [3,9]. Previous research performed in animals has shown the effects of resistin on the insulin/ IGF-1 signaling pathway in insulin-sensitive tissues (e.g., muscle, fat, and liver) [10]. However, it is much of the controversy regarding IL-6 and insulin sensitivity [11].

Studies conducted on postmenopausal women without RA have shown that total serum OC is negatively associated with insulin resistance indices [12]. However, the associations between carbohydrate metabolic indices and OC in postmenopausal women with RA are less recognised. We hypothesize that inflammatory factors may contribute to this process. RA is characterized by impaired bone formation [13], and in vitro studies [14] showed that pro-inflammatory cytokines reduced OC expression. Therefore, the purpose of this study was to determine the relationship of osteocalcin with insulin resistance, IGF-1 and inflammatory markers in women with RA.

\section{Materials and Methods}

\section{Patient selection and basic measurements}

The study population comprised of 35 postmenopausal women with RA, aged between 50 and 65 years, diagnosed according to the American College of Rheumatology criteria [15] which was in force at the time of this research. We included patients admitted to the Rheumatology Department within two consecutive months, who agreed to participate in this research. We excluded patients who presented disease known to affect bone metabolism like diabetes mellitus, hyperthyroidism and hyperthyroidism and parathyroidism, received biologic or bisphosphonate therapies, and underwent hormone replacement therapy.

The study protocol was approved by the Ethics Committee for Human Studies at K. Marcinkowski University of Medical Sciences in Poznan. All the participants provided informed consent. The disease activity score (DAS28) was determined by using the number of swollen and tender joints, score on the visual analogue scale (VAS), and erythrocyte sedimentation rate (ESR) [16].

*Corresponding author: Alicja Nowak, Department of Hygiene, Chair of Physiology, Biochemistry and Hygiene, University School of Physical Education, Królowej Jadwigi str. 27/39-61-871 Poznań, Poland, Tel: +48 61 8355179; Fax +48 618355158; E-mail: anowak@awf.poznan.pl

Received July 09, 2013; Accepted August 25, 2013; Published September 02 2013

Citation: NowakA, Straburzyńska-Lupa A, Pilaczyńska-SzcześniakŁ, Romanowski W (2013) Is Osteocalcin Implicated in the Regulation Of Energy Metabolism in Active Rheumatoid Arthritis? Metabolomics 3: 122. doi:10.4172/2153-0769.1000122

Copyright: (C) 2013 Nowak A, et al. This is an open-access article distributed under the terms of the Creative Commons Attribution License, which permits unrestricted use, distribution, and reproduction in any medium, provided the original author and source are credited. 


\section{Analytical procedures}

Blood was collected fasting, between 8 and 10 a.m. Samples were centrifuged at $1540 \mathrm{rcf}$ and $4^{\circ} \mathrm{C}$. In the serum samples, stored at $-70^{\circ} \mathrm{C}$, the following indices were measured: glucose concentrations with a commercially available assays (Cormay, Poland), insulin, IGF-1, and insulin-like growth factor binding protein-3 (IGFBP-3) levels with radioimmunoassays (BioSource Europe S.A., Belgium), rheumatoid factor (RF) levels using BioSystems kit (Spain), and high sensitivity C-reactive protein (hsCRP) concentrations with a high sensitive nephelometer metod (Orion Diagnostica, Finland). ESR was measured using Medlab Products kit (Poland). Serum concentrations of resistin and high sensitivity IL- 6 were analyzed by immunoenzymatic ELISA method using kits by R\&D Systems (UK) and intact OC using a kit by Bender MedSystems (Austria) (Lombardi et al 2012). The insulin sensitivity index HOMA-IR (homeostasis model assessment of insulin resistance) was calculated [17].

\section{Statistical analysis}

The Kolmogorov-Smirnov test was used to check the data for normal distribution, whereas the Levene's test for homogeneity of variance. The calculation of Pearson correlation coefficient and the Spearman rank test were used to determine associations for normally and non-normally, respectively, distributed variables. All analyses were performed using Statistica 8.0 package, and a $P$ value of $<0.05$ was considered statistically significant.

\section{Results}

Table 1 presents clinical and biochemical characteristics of RA patients. In the group of women with RA, significant negative correlations were noted between the OC and resistin levels $(\mathrm{p}<0.05)$, glucose and resistin levels ( $\mathrm{p} \leq 0.01)$, glucose and IL-6 levels $(\mathrm{p} \leq 0.01)$, IL-6 and IGFBP-3 levels $(\mathrm{p}<0.05)$ (Table 2$)$. The positive correlations were found between insulin level and disease duration $(p<0.05)$, HOMA-IR level and disease duration ( $\mathrm{p}<0.05)$, IGF-1 and IGFBP-3 levels ( $p \leq 0.01)$, the IGF-1/IGFBP- 3 ratio and ESR $(p \leq 0.01)$, and the IGF-1/IGFBP-3 ratio and hsCRP levels $(\mathrm{p}<0.05)$.

\section{Discussion}

In the group of women with RA we found positive correlations between insulin resistance indices and disease duration, which may confirm the results of other studies that showed that RA leads to metabolic carbohydrate disturbances [18]. However, no associations were observed between $\mathrm{OC}$ and carbohydrate metabolic indices. We found the negative relationship of $\mathrm{OC}$ with resistin levels, which may be a part of a complex energy metabolism-bone network in patients with RA. This association is in line with results obtained by other authors in the group of old patients with hip fractures [19] or in obese children and adolescents [20]. However, the mechanism of resistin contribution in inhibiting bone formation seems unclear. Vergely et al. [21] showed that $\mathrm{OC}$ is also down regulated by steroid therapy. In previous our study we observed the inverse correlation between OC and resistin only in patients with steroids treatment when we divided them into subgroups using or no using glucocorticoid therapy [22]. Thus we cannot excluded that adverse effect of glucocorticoid treatment on bone tissue is associated with resistin in our patients.

In the general population, the development of insulin resistance is a major metabolic consequence of obesity, particularly proinflammatory cytokines secreted from macrophages and/or adipocytes, between others resistin and IL-6 [9]. However, in the present study, insulin resistance

\begin{tabular}{|c|c|}
\hline & RA group \\
\hline Age [years] & $56.6(3.6)$ \\
\hline Body mass $[\mathrm{kg}]$ & $69.6(11.7)$ \\
\hline Body height $[\mathrm{cm}]$ & $159.9(4.6)$ \\
\hline BMI $\left[\mathrm{kg} / \mathrm{m}^{2}\right]$ & $27.2(4.6)$ \\
\hline Waist circumference [cm] & $89.4(11.3)$ \\
\hline Menopause [years] & $50.0(49.0-53.0)$ \\
\hline Disease duration [years] & $11.3(7.27)$ \\
\hline DAS28 & $5.13(1.03)$ \\
\hline Rheumatoid Factor positive n (\%) & $26(74)$ \\
\hline $\mathrm{ESR}[\mathrm{mm} / \mathrm{h}]$ & $30.0(15.0-52.0)$ \\
\hline hsCRP [mg/l] & $12.0(8.0-28.0)$ \\
\hline Interleukin 6 [pg/ml] & $8.51(5.0-16.1)$ \\
\hline Resistin [ng/ml] & $16.29(11.17-25.10)$ \\
\hline Osteocalcin [ng/ml] & $2.74(1.95)$ \\
\hline Glucose $[\mathrm{mmol} / \mathrm{l}]$ & $4.96(0.73)$ \\
\hline Insulin [mIU/ml] & $10.00(7.88-13.39)$ \\
\hline HOMA-IR & $2.23(1.64-2.75)$ \\
\hline IGF-1 [mg/ml] & $165.76(36.00)$ \\
\hline IGFBP-3 [mg/ml] & $3894.29(631.86)$ \\
\hline IGF-1/IGFBP-3 & $0.04(0.01)$ \\
\hline \multicolumn{2}{|l|}{ Current treatment } \\
\hline Prednisolone n (\%) & $21(60)$ \\
\hline Prednisolone [mg/daily] & $6.3(2.5)$ \\
\hline
\end{tabular}

Results are expressed as mean (SD) for normally distributed variables and as median (interquartile range) for non-normally distributed variables; BMI, body mass index; DAS28, disease activity score; ESR, erythrocyte sedimentation rate; hsCRP high sensitivity C-reactive protein; HOMA-IR,, homeostasis model assessment of insulin resistance; IGF-1, insulin-like growth factor-1; IGFBP-3, insulin-like growth factor binding protein-3; DMARDs, disease-modifying anti-rheumatic drugs

Table 1: Clinical and biochemical characteristics women with RA.

\begin{tabular}{lcc}
\hline Parameters & $r$ & $P$-value \\
\hline OC / resistin & -0.36 & 0.0341 \\
glucose / resistin & -0.49 & 0.0030 \\
glucose / IL-6 & -0.49 & 0.0030 \\
insulin / disease duration & 0.40 & 0.0168 \\
HOMA-IR / disease duration & 0.36 & 0.0340 \\
IL-6 / IGFBP-3 & -0.35 & 0.0387 \\
IGF-1 / IGFBP-3 & 0.43 & 0.0091 \\
IGF-1 to IGFBP-3 ratio / ESR & 0.46 & 0.0057 \\
IGF-1 to IGFBP-3 ratio / hsCRP & 0.39 & 0.0215
\end{tabular}

ESR, erythrocyte sedimentation rate; hSCRP, high sensitivity C-reactive protein HOMA-IR, homeostasis model assessment of insulin resistance; IGF-1, insulinlike growth factor-1; IGFBP-3, insulin-like growth factor binding protein-3,;IL-6, interleukin 6; OC, osteocalcin

Table 2: Relationships between biochemical indices, ESR and disease duration in patients with RA.

indices did not correlate with body mass parameters. Moreover, we found the negatively associations of resistin and IL-6 levels with glucose levels. Experiments in primary human cultured muscle have demonstrated that IL-6 increases glucose uptake, enhances glycogen synthesis and also increases skeletal muscle $\beta$-oxidation of fatty acids [23] and therefore their deleterious effects on glucose metabolism are discussed [11]. On the other hand the excess production of IL-6 may provide an explanation for some of the clinical manifestations associated with active RA, including weight loss and poor appetite [24].

Matsumoto and Tsurumoto [25] have showed a weak positive association of OC with IGFBP-3, a predominant carrier of IGF-1 in serum, in women with RA, suggesting its relationship with the activity 
Citation: Nowak A, Straburzyńska-Lupa A, Pilaczyńska-Szcześniak Ł, Romanowski W (2013) Is Osteocalcin Implicated in the Regulation Of Energy Metabolism in Active Rheumatoid Arthritis? Metabolomics 3: 122. doi:10.4172/2153-0769.1000122

Page 3 of 3

of osteoblasts. We did not observed any correlations between levels of OC and IGF-1 or IGFBP-3 but we found the negative relationship between IGFBP-3 and IL- 6 levels and positive correlations between IGF-1/IGFBP-3 ratio and ESR and hsCRP. It has been demonstrated that chronic overproduction of IL-6 causes decreased IGFBP-3 levels, resulting in a decreased association of IGF-I in the $150-\mathrm{kDa}$ complex [26]. In patients with systemic juvenile idiopathic arthritis levels of intact IGFBP-3 have inversely correlated with serum IL-6, CRP and ESR and positively correlated with IGF-I levels as in our study in RA.

We can not exclude the contribution of pharmacotherapy on our results. Although it has been documented that glucocorticosteroids are responsible for glucose intolerance in RA [27], the low doses of steroids used by our patients and their beneficial effect on inflammation might counteract their effects on bone formation and insulin resistance [28]. Moreover, Russo and colleagues [29] have demonstrated that treatment with low doses of methotrexate may improve carbohydrate metabolism by increasing the expression of skeletal muscle glucose transporter type 4.

In conclusion, the present study suggests that inflammatory factors may modify in distinct ways the relationship between osteocalcin and carbohydrate metabolism in patients with RA. However, limitations of this study are lack of control group, small sample size and that we did not measure uncarboxylated OC. The relationship between OC and energy metabolism in patients in RA should be studied further.

\section{Acknowledgments}

The authors declare no conflict of interest.

\section{References}

1. Solomon DH, Love TJ, Canning C, Schneeweiss S (2010) Risk of diabetes among patients with rheumatoid arthritis, psoriatic arthritis and psoriasis. Ann Rheum Dis 69: 2114-2117.

2. Romas E, Gillespie MT, Martin TJ (2002) Involvement of receptor activator of $\mathrm{NFKB}$ ligand and tumor necrosis factor- $\alpha$ in bone destruction in rheumatoid arthritis. Bone 30 : 340-346.

3. Chung CP, Oeser A, Solus JF, Gebretsadik T, Shintani A, et al. (2008) Inflammation-associated insulin resistance: differential effects in rheumatoid arthritis and systemic lupus erythematosus define potential mechanisms. Arthritis Rheum 58: 2105-2112.

4. Ahmed TA, Buzzelli MD, Lang CH, Capen JB, Shumate ML, et al. (2007) Interleukin-6 inhibits growth hormone-mediated gene expression in hepatocytes. Am J Physiol Gastrointest Liver Physiol 292: G1793-1803.

5. Lee NK, Sowa H, Hinoi E, Ferron M, Ahn JD, et al. (2007) Endocrine regulation of energy metabolism by the skeleton. Cell 130: 456-469.

6. Kadowaki T, Tobe K, Honda-Yamamoto R, Tamemoto $H$, Kaburagi $Y$, et al (1996) Signal transduction mechanism of insulin and insulin-like growth factor-1. Endocr J 43: S33-S41.

7. Clemens TL, Karsenty G (2011) The osteoblast: an insulin target cell controlling glucose homeostasis. J Bone Miner Res 26: 677-680.

8. Šenolt L, Housa D, Vernerová Z, Jirásek T, Svobodová R, et al. (2007) Resistin in rheumatoid arthritis synovial tissue, synovial fluid and serum. Ann Rheum Dis 66: $458-463$.

9. Rabe K, Lehrke M, Parhofer KG, Broedl UC (2008) Adipokines and insulin resistance. Mol Med 14: 741-751.

10. Qatanani M, Szwergold NR, Greaves DR, Ahima RS, Lazar MA (2009) Macrophage-derived human resistin exacerbates adipose tissue inflammation and insulin resistance in mice. J Clin Invest 119: 531-539.
11. Pedersen BK (2007) Interleukin-6 does/does not have a beneficial role in insulin sensitivity and glucose homeostasis. J Appl Physiol 102: 814-816.

12. Im JA, Yu BP, Jeon JY, Kim SH (2008) Relationship between osteocalcin and glucose metabolism in postmenopausal women. Clin Chim Acta 396: 66-69.

13. Neve A, Corrado A, Cantatore FP (2011) Osteoblast physiology in normal and pathological conditions. Cell Tissue Res 343: 289-302.

14. Li YP, Stashenko P (1992) Proinflammatory cytokines tumor necrosis factoralpha and IL-6, but not IL-1, down-regulate the osteocalcin gene promoter. $J$ Immunol 148: 788-794.

15. Arnett FC, Edworthy SM, Bloch DA, McShane DJ, Fries JF, et al. (1988) The American Rheumatism Association 1987 revised criteria for the classification of rheumatoid arthritis. Arthritis Rheum 31: 315-324.

16. Prevoo ML, van 't Hof MA, Kuper HH, van Leeuwen MA, van de Putte LB, et al (1995) Modified disease activity scores that include twenty-eight-joint counts. Development and validation in a prospective longitudinal study of patients with rheumatoid arthritis. Arthritis Rheum 38: 44-48.

17. Lombardi G, Lanteri P, Colombini A, Banfi G (2012) Blood biochemical markers of bone turnover: pre-analytical and technical aspects of sample collection and handling. Clin Chem Lab Med 50: 771-789.

18. Matthews DR, Hosker JP, Rudenski AS, Naylor BA, Treacher DF, Turner RC (1985) Homeostasis model assessment: insulin resistance and betacell function from fasting plasma glucose and insulin concentration in man Diabetes 28: 412-419.

19. Fisher A, Srikusalanukul W, Davis M, Smith $P$ (2012) Interactions between serum adipokines and osteocalcin in older patients with hip fracture. International Journal of Endocrinology.

20. Flemming GM, Petzold S, Meigen C, Körner A, Kiess W, et al. (2012) Is circulating osteocalcin related to adipokines and overweight/obesity in children and adolescents? Exp Clin Endocrinol Diabetes 120: 383-387.

21. Vergély $\mathrm{N}$, Lafage-Proust $\mathrm{MH}$, Caillot-Augusseau A, Millot L, Lang $\mathrm{F}$, et al. (2002) Hypercorticism blunts circadian variations of osteocalcin regardless of nutritrional status. Bone 30: 428-435.

22. Straburzyńska-Lupa A, Nowak A, Romanowski W, Korman P, PilaczyńskaSzcześniak $\nvdash$ (2012) A study of the link between bone turnover markers and bone mineral density with inflammation and body mass in postmenopausal women with active rheumatoid arthritis. J Bone Miner Metab 31: 169-176.

23. Al-Khalili L, Bouzakri K, Glund S, Lönnqvist F, Koistinen HA, et al. (2006) Signaling specificity of interleukin- 6 action on glucose and lipid metabolism in skeletal muscle. Mol Endocrinol 20: 3364-3375.

24. Hennigan S, Kavanaugh A (2008) Interleukin-6 inhibitors in the treatment of rheumatoid arthritis. Ther Clin Risk Manag 4: 767-775.

25. Matsumoto T, Tsurumoto T (2002) Inappropriate serum levels of IGF-I and IGFBP-3 in patients with rheumatoid arthritis. Rheumatology (Oxford) 41: 352 353

26. De Benedetti F, Meazza C, Oliveri M, Pignatti P, Vivarelli M, Alonzi T (2001) Effect of IL-6 on IGF binding protein-3: a study in IL-6 transgenic mice and in patients with systemic juvenile idiopathic arthritis. Endocrinology, 142: 48184826

27. Pagano G, Bruno A, Cavallo-Perin P, Cesco L, Imbimbo B (1989) Glucose intolerance after short-term administration of corticosteroids in healthy subjects. Prednisone, deflazacort, and betamethasone. Arch Intern Med 149: 1098-1101.

28. Engvall IL, Svensson B, Tengstrand B, Brismar K, Hafström I, et al. (2008) Impact of low-dose prednisolone on bone synthesis and resorption in early rheumatoid arthritis: experiences from a two-year randomized study. Arthritis Res Ther 10: R128.

29. Russo GT, Minutoli L, Bitto A, Altavilla D, Alessi E, et al. (2012) Methotrexate increases skeletal muscle GLUT4 expression and improves metabolic control in experimental diabetes. Journal of Nutrition and Metabolism 